\title{
Avaliação da acessibilidade das calçadas nas praças da Zona de Comércio Central (ZCC), Maringá, PR, Brasil
}

\author{
Evaluación de la accesibilidad de las calzadas en las plazas de la \\ zona de comercio central (ZCC), Maringá, PR, Brasil
}

\section{Accessibility assessment of sidewalks in the Commercial Center Quartier (ZCC), Maringá, PR, Brazil}

\author{
Gabriel Guilherme Magalhães Santos \\ gabriel_isnou@hotmail.com \\ Faculdade de Engenharia e Inovação Técnico Profissional, FEITEP, Maringá, PR \\ Ricardo Massulo Albertin \\ prof.ricardo@feitep.edu.br \\ Faculdade de Engenharia e Inovação Técnico Profissional, FEITEP, Maringá, PR \\ Hugo Gabriel Fernandes Viotto \\ enghugo.orbe@gmail.com \\ Universidade Estadual de Maringá, UEM, Maringá, PR \\ Frederico Fonseca da Silva \\ frederico.silva@ifpr.edu.br \\ Instituto Federal do Paraná, IFPR, Curitiba, PR
}

\begin{abstract}
Resumo: No Brasil cerca de $24 \%$ da população declara ter algum tipo de deficiência. Neste contexto, a infraestrutura urbana das urbes deve estar preparada para a mobilidade dessas pessoas. Deslocamento feitos a pé é encarado muitas vezes por calçadas inexistentes ou intransitáveis, tornando-se um risco para pedestres. Objetivouse nesta pesquisa analisar as condições das calçadas localizadas no entorno das praças Raposo Tavares e Napoleão Moreira da Silva localizadas na Zona de Comércio Central (ZCC), na cidade de Maringá, quanto a acessibilidade e demais critérios normativos estabelecidos pela NBR 9050 (2015) e NRM U-20001 (2016). Os procedimentos metodólogos compreenderam, levantamento in loco, no qual observou-se as condições das calçadas e comparou-se com as exigências estabelecidas pelas normas técnicas. Os resultados demonstraram a existência de não conformidades em ambas as áreas analisadas.
\end{abstract}

Palavras-chave: Planejamento Urbano; Infraestrutura urbana; Gestão; Mobilidade Urbana.

Resumen: En Brasil cerca del $24 \%$ de la población declara tener algún tipo de discapacidad. En este contexto, la infraestructura urbana de las ciudades debe estar preparada para la movilidad de esas personas. El desplazamiento a pie se ve a menudo por aceras inexistentes o intransitables, convirtiéndose en un riesgo para los peatones. 
En esta investigación se analizaron las condiciones de las calzadas ubicadas en el entorno de las plazas Raposo Tavares y Napoleón Moreira da Silva ubicadas en la ZCC en la ciudad de Maringá, en cuanto a accesibilidad y demás criterios normativos establecidos por la NBR 9050 (2015) y NRM U-20001 (2016). Los procedimientos metodológicos comprendieron, levantamiento in loco, en el cual se observaron las condiciones de las calzadas y se comparó con las exigencias establecidas por las normas técnicas. Los resultados demostraron la existencia de incumplimiento en ambas áreas analizadas.

Palabras clave: Planificación Urbana, Infraestructura Urbana, Gestión, Movilidad urbana.

\begin{abstract}
In Brazil, about $24 \%$ of the population declares to have some type of disability. In this context, the urban infrastructure of the cities must be prepared for the mobility of these people. Displacement made on foot is often faced by non-existent or impassable sidewalks, making it a risk for pedestrians. The objective of this research was to analyze the conditions of sidewalks located in the surroundings of the places Raposo Tavares, and Napoleão Moreira da Silva located in the ZCC in the city of Maringá, regarding accessibility and other normative criteria established by NBR 9050 (2015) and NRM U-20001 (2016). The methodological procedures included an on-site survey, in which the conditions of the sidewalks were observed and compared with the requirements established by the technical standards. The results demonstrated the existence of non-compliance in both analyzed areas.
\end{abstract}

Keywords: Urban Planning; Urban Infrastructure; Management; Urban mobility.

\title{
INTRODUÇÃO
}

No Brasil, o processo de urbanização resultou em um deslocamento de milhares de pessoas das zonas rurais para as cidades. Em 1890 a população urbana do Brasil era de $10 \%$ e atualmente $83 \%$ dos brasileiros vivem em cidades (ANGEOLETTO et al., 2016). Entre 1970 e 2010 o aumento da população residente em zona urbana no Brasil passou de aproximadamente $56 \%$ para 84,4\% (IBGE, 2010). Segundo Mark (2008) até 2030, de acordo com projeções da divisão de população da ONU, as regiões que concentram países em desenvolvimento irão experimentar um forte crescimento urbano, chegando em $2050 \mathrm{a}$ dois habitantes urbanos para cada habitante rural.

O crescimento demográfico das cidades muitas vezes resulta em impactos significativos na vida da população de acordo com a maneira pela qual cidades são projetadas e planejadas. Devido ao rápido crescimento populacional e de veículos automotores, as atividades de comércio e serviços acabam se deslocando para as áreas periféricas da cidade, e em meio a disputa pelo espaço urbano o conceito de mobilidade e acessibilidade fica cada vez mais esquecido (ALMEIDA; BORTOLUZZI; GIACOMINI, 2013; RUMBLE et al., 2019).

De acordo com Gomide e Galindo (2013, p.1), “o conceito de mobilidade urbana refere-se às condições de deslocamento das pessoas e bens nas cidades, independentemente do modo de transporte utilizado (coletivo ou individual, motorizado ou não motorizado)" [...] "Isso significa que a mobilidade urbana está relacionada à acessibilidade, ao direito e à necessidade que as pessoas têm de se locomover pelas cidades". 
A Constituição Federal de 1988 é clara em seu Art. 144., que deve ser assegurado ao cidadão o direto à mobilidade urbana eficiente. Ou seja, é um direito constitucional (BRASIL, 1988). A Lei Federal 12.587, de 2012, instituiu a Política Nacional de Mobilidade e criou o Sistema Nacional de Mobilidade Urbana, que visa organizar os modos de transporte, a infraestrutura e os serviços para proporcionar melhoria nas condições urbanas da população no que se refere à acessibilidade e à mobilidade. No Art. 24 é mencionada a exigência de que os municípios elaborem o Plano de Mobilidade Urbana, contemplando alguns objetivos e diretrizes, dentre os quais garantir a acessibilidade para pessoas com deficiência e restrição de mobilidade (BRASIL, 2002).

Segundo o Programa Brasileiro de Acessibilidade Urbana (2006), ao se analisar o espaço urbano facilmente se encontram situações que se tornam inacessíveis a um grande grupo de pessoas limitadas no seu direito de ir e vir pelo fato do espaço urbano os desconsiderar como usuários em potencial. Estas situações passam despercebidas a quem não possui nenhuma limitação em sua mobilidade ou que não tenha nenhum caso no seu círculo social ou familiar. Dentro desse contexto, muitas vezes, é necessária uma readequação do espaço urbano público destinado a pessoas com mobilidade reduzida, o que passa por uma conscientização e um rigor maior na aplicação das normas de acessibilidade por parte dos profissionais.

Segundo o IBGE, cerca de $24 \%$ da população brasileira, declarara ter pelo menos uma das deficiências investigadas (visual, auditiva, motora e mental) e na cidade de Maringá a proporção é pouco maior , de aproximadamente 25\% (IBGE, 2010). Em entrevista realizada pelo DataSenado com 1.165 pessoas com algum tipo de deficiência e cerca de $76 \%$ delas acredita não ter seus direitos respeitados (BRASIL, 2010). Ou seja, o que seria um direito constitucional, passa a ser muitas vezes como algo utópico.

Além disso, de acordo com o IBGE (2018), a população brasileira vem passando por um processo de envelhecimento. Estima-se que até o ano de 2060, o percentual de pessoas com mais de 65 anos passará dos atuais 9,2\% para 25,5\%. Ou seja, as cidades devem possuir infraestrutura adequada para esta mudança na forma de vivência e locomoção das pessoas com mobilidade reduzida.

A falta de acessibilidade acaba desencadeando problemas de cunho social e psicológico, como isolamento nos domicílios e desmotivação pelas dificuldades de locomoção. É necessário que essas pessoas não se sintam excluídas do convívio social, que se sintam livres, com capacidade de ir e vir a todo espaço urbano público, sem obstáculos, dificuldades e com conforto.

Assim sendo, e verificando a importância da mobilidade e acessibilidade como forma integrante do processo de planejamento urbano, este estudo avaliou as calçadas do entorno das praças Napoleão Moreira da Silva e Raposo Tavares, localizadas na Zona de Comércio Central (ZCC), na cidade média de Maringá, com o objetivo específico de compará-las quanto à acessibilidade prescrita nas normas ABNT NBR 9050/2015 e NRM U-20001. 


\section{PROCEDIMENTOS METODOLÓGICOS}

\section{Caracterização das áreas de estudo}

A cidade de Maringá localiza-se no estado do Paraná, Sul do Brasil (Fig. 1). É considerada uma cidade de médio porte, com população estimada de aproximadamente 417.010 habitantes e uma área territorial de $487,052 \mathrm{~km}^{2}$, o que resulta em uma densidade demográfica de 733,14 hab./ km² (IBGE, 2019).

Maringá foi fundada 1947, como Distrito de Mandaguari, e elevada à Vila em 1948. Foi efetivada como município em 1951, resultado de um projeto de colonização implantado pela Companhia de Terras Norte do Paraná/Companhia Melhoramentos Norte do Paraná - CTNP/CMNP (IBGE, 2019). Segundo Meneguetti e Rego (2008), o projeto urbano de Jorge de Macedo Vieira foi inspirado pela 'arte inglesa de projetar cidades', de Barry Parker e Raymond Urwin, a qual considera a proposta clássica de cidade-jardim de elevar os padrões de conforto e saúde dos trabalhadores numa combinação saudável, natural e econômica da vida rural e urbana, incluindo praças (HOWARD, 1902).

Figura 1: Localização do município de Maringá, PR.

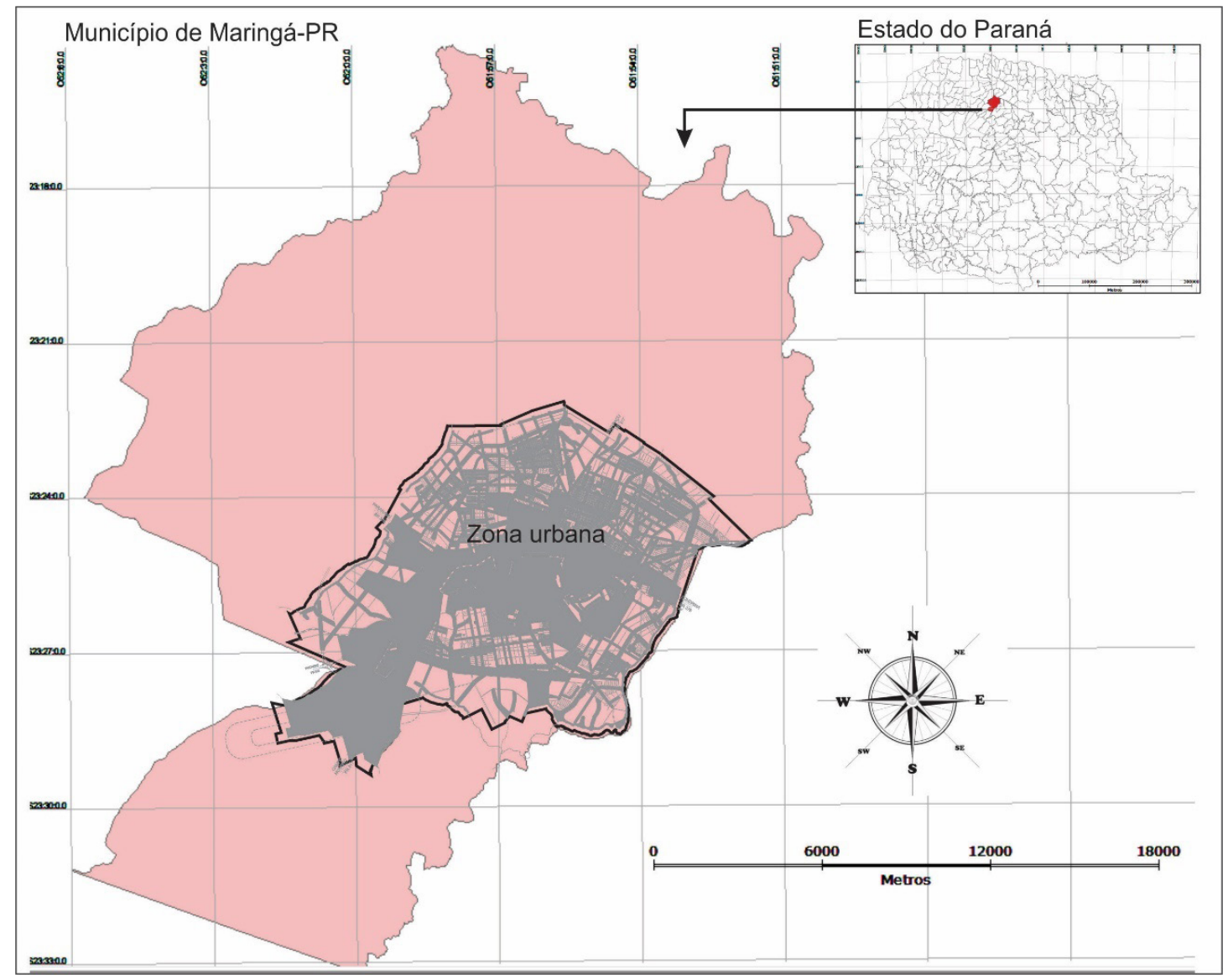

Fonte: os autores

Considera-se que as calçadas devem ser desenhadas aos usuários, ou seja, aos pedestres, dimensionadas em função do uso e ocupação do solo. Em zonas multifamiliares 
ou zonas comerciais fatalmente ocorrerá uma intensa circulação de pedestres, daí a importância de dimensionar adequadamente e definir o tipo e mobiliário urbano apropriado (CASTELLO, 2008).

Quando se trata de calçadas em praças, há de considerar que cada praça possui uma 'identidade' própria, determinada por inúmeros fatores, dentre os quais cita-se: criatividade; localização; se praça temática ou não; característica da população transeuntes; características e aptidão do terreno; equipamentos e estruturas existentes; características do uso e ocupação do solo no entorno; disponibilidade de recursos financeiros; disponibilidade de recursos humanos (DE ANGELIS; DE ANGELIS NETO, 1999).

Considera-se ainda que é sobre o passeio que estão localizadas a arborização viária e mobiliário urbano, tais como: lixeiras, bancos, placas de sinalização, caixas de coleta de correio, pontos de parada do sistema de transporte público, entre outros (CASTELLO, 2008)

Neste aspecto, definiu-se como locais de estudo as calçadas no entorno de duas praças da Zona de Comércio Central de Maringá - Praça Raposo Tavares e Praça Napoleão Moreira da Silva (Fig. 2).

Figura 2: Localização das áreas de estudo - praças Raposo Tavares e Napoleão Moreira da Silva.

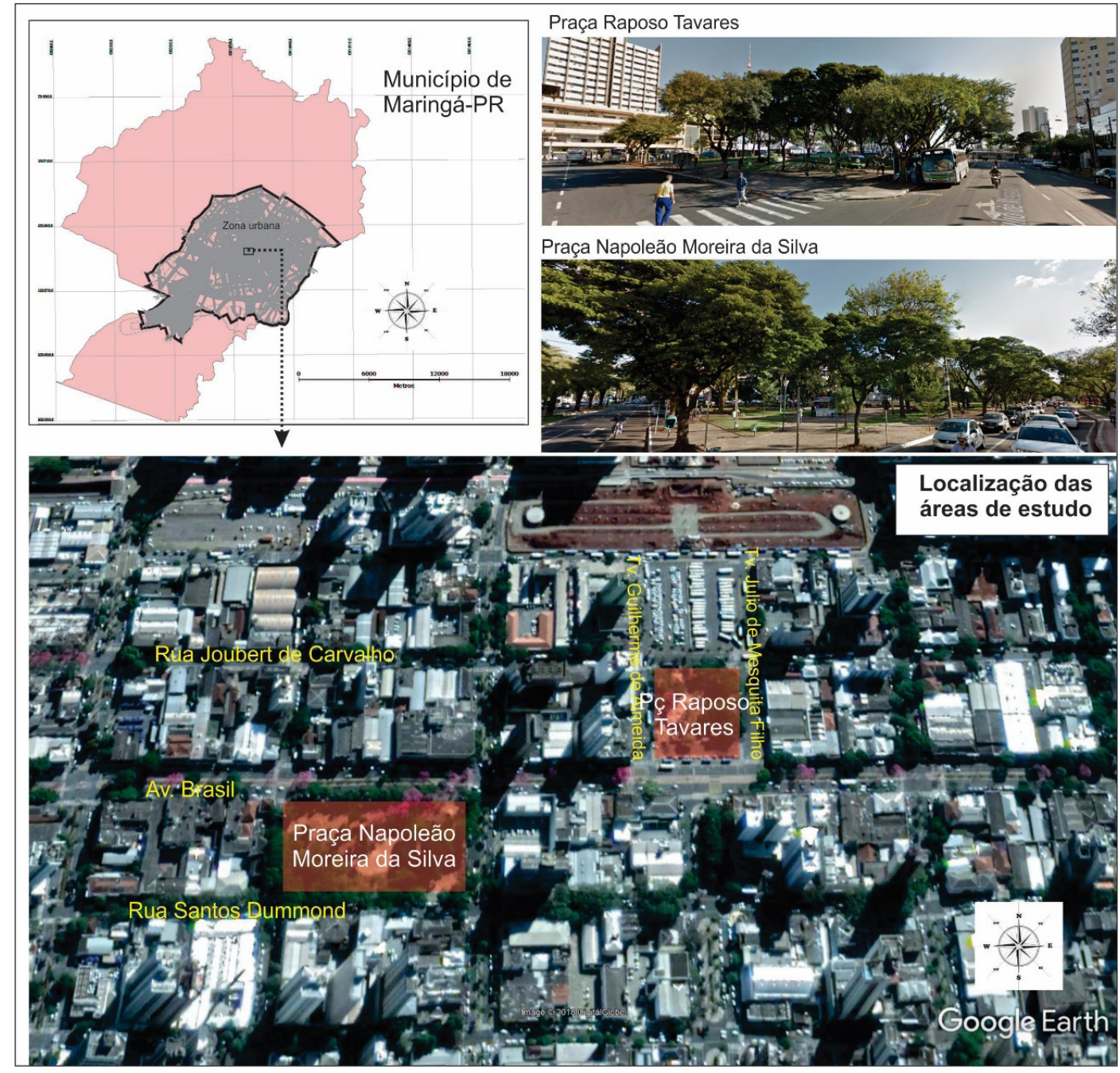

Fonte: adap. de GOOGLE Earth, 2018. 
A praça Raposo Tavares possui área de aproximadamente $4.610 \mathrm{~m}^{2}$, sendo atualmente utilizada principalmente para fins comerciais e sociais (feiras de agroindústria e artesanatos), religiosos (cultos e eventos), estruturas de atração de pessoas (abrigos de ônibus, área de embarque de táxi) e local de passagem. A praça Napoleão Moreira da Silva possui área aproximada de $11.520 \mathrm{~m}^{2}$, sendo atualmente utilizada principalmente para fins comerciais e sociais (feiras de agroindústria, artesanatos e pontos fixo de comercialização de sorvetes), estruturas de atração de pessoas (área de embarque de táxi) e local de passagem.

A praça Raposo Tavares foi criada em 1947 e dez anos depois recebeu seu primeiro monumento, a Fonte Luminosa (Fig. 3), um ponto de atração que atualmente não existe mais.

Figura 3: Praça Raposo Tavares em 10 de maio de 1957, inauguração da Fonte Luminosa.

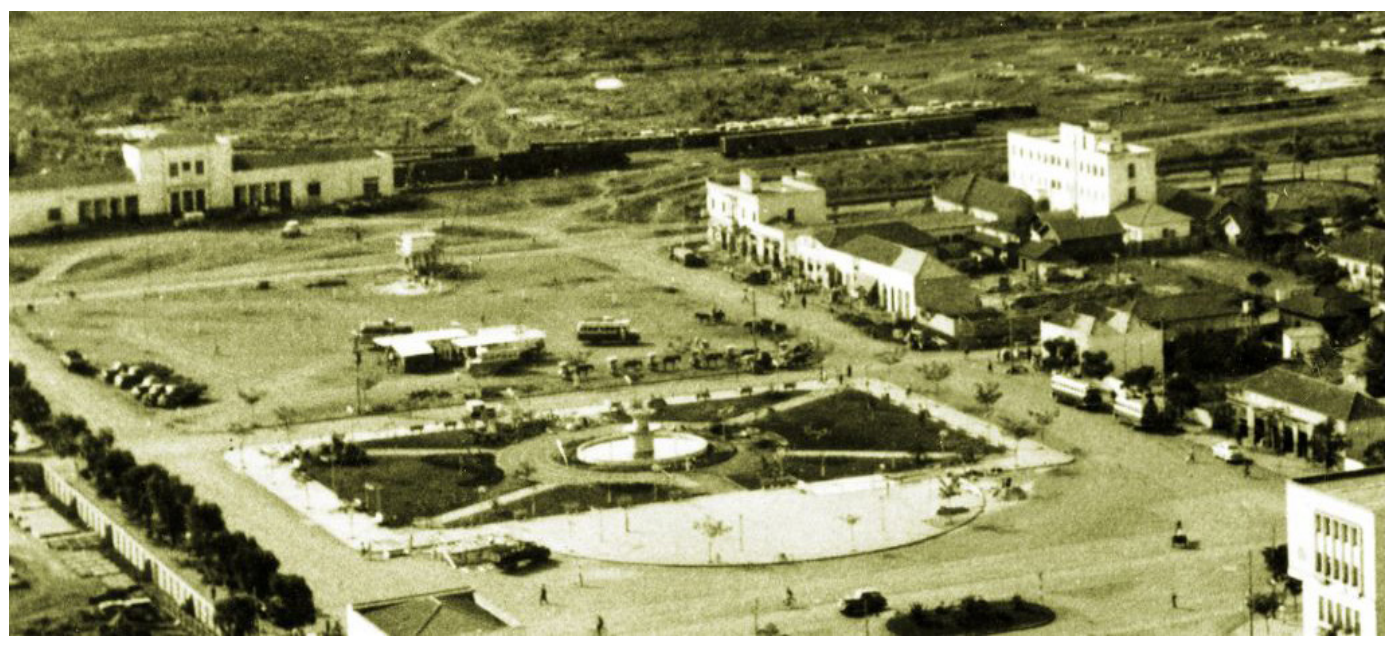

Fonte: Maringá histórica, 2018.

A praça Napoleão Moreira da Silva, que era popularmente chamada de praça da rodoviária (BOVO, 2009). Por meio da Lei 32/1957 foi nomeada "Praça Napoleão Moreira da Silva”. Em 1962 passou por um processo de reurbanização (MARINGÁ HISTÓRICA, 2018). A Figura 4 mostra a praça Napoleão Moreira da Silva no ano de 1962, após a reurbanização.

Figura 4: Praça Napoleão Moreira da Silva em 1962, quando foi reinaugurada.

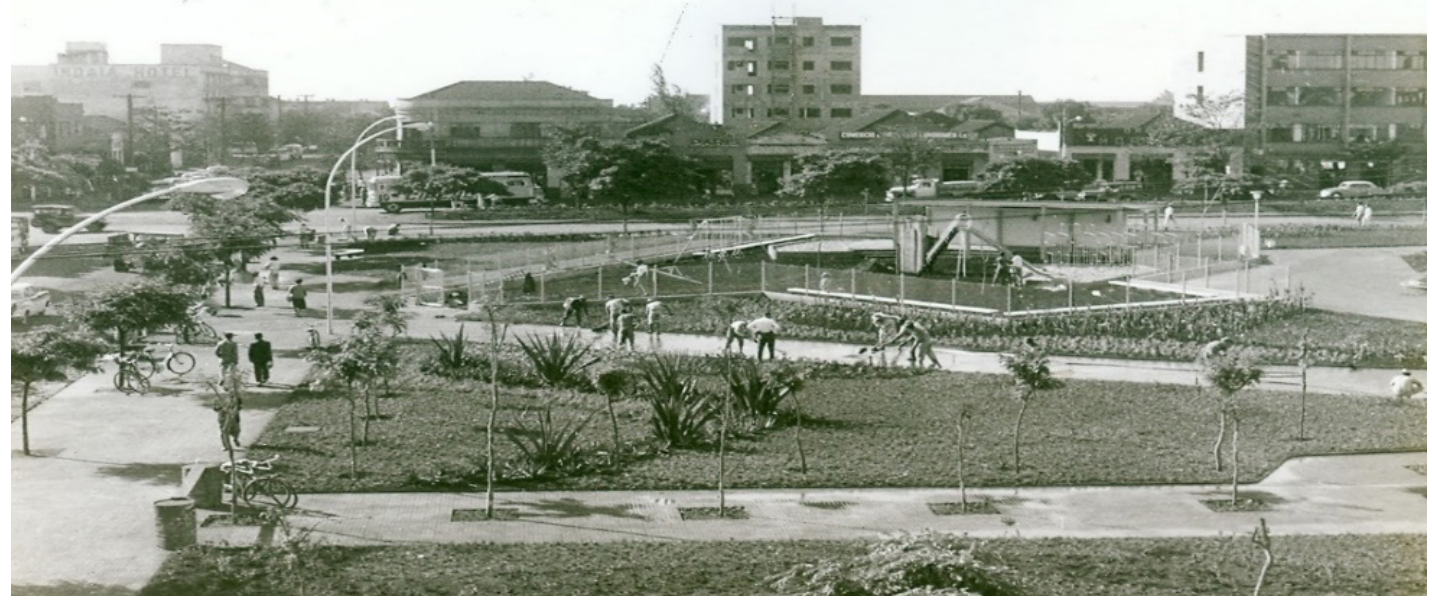

Fonte: Maringá histórica, 2018. 


\section{Parâmetros utilizados para levantamento in loco}

O estudo das calçadas nas praças pressupõe três pontos de análise: (1) levantamento quantitativo de árvores e guias rebaixadas; (2) avaliação qualitativa de atendimento as normas; (3) observação do cotidiano da praça.

A análise das calçadas foi baseada nas seguintes normativas:

- Associação Brasileira de Normas Técnica (ABNT) NBR 9050/2015, Acessibilidade a edificações, mobiliário, espaços e equipamentos urbanos.

- Norma Regulamentadora Municipal (NRM) U-20.001 da Prefeitura Municipal de Maringá, "das calçadas - desenho, acessibilidade e mobilidade", que regulamentou os Arts. 18, 22, e o § único do art. 30, da LC n $n^{0}$. 1.045/2016. Essa norma tem como objetivo "[...] "regulamentar o dimensionamento e demais critérios relativos ao desenho, acessibilidade, mobilidade e ao acesso de veículos em edificação, referentes às calçadas no Município de Maringá." (MARINGÁ, 2016, p.1). Esta preconiza quatro modelos de calçadas (Fig. 5) e conforme o levantamento a praça Raposo Tavares enquadra-se no modelo de $4,00 \mathrm{~m}$ e a praça Napoleão Moreira da Sila no modelo de 5,00 m.

O levantamento utilizou aspectos de referência de localização, como: árvores, pontos de ônibus, rebaixamentos de calçada, etc. Tendo como base as dimensões e padrões das caçadas, realizou-se medições com de trena, nível e linha para orientação do cálculo da inclinação. Por fim, confeccionou-se um croqui de cada uma das praças e foram registradas fotografias das situações de não conformidade.

Figura 5. Padrões de calçadas para a cidade de Maringá, PR.

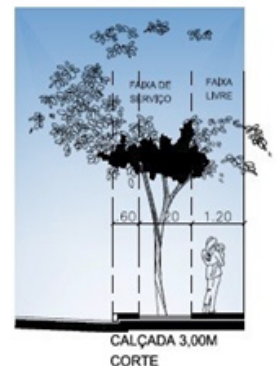

CORTE

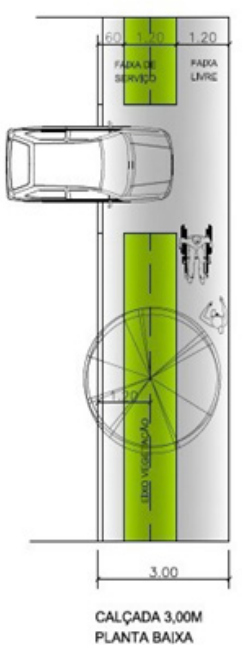

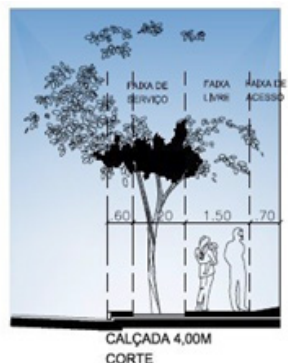

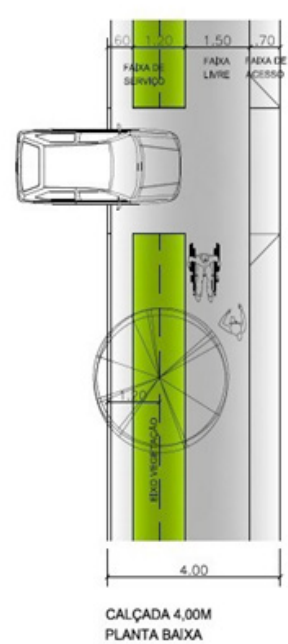

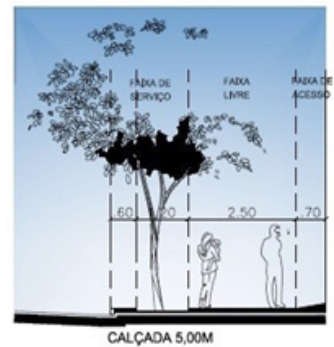

CORTE

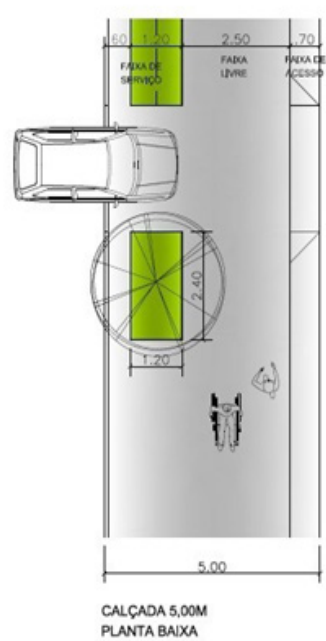

CALCADA 5,00M
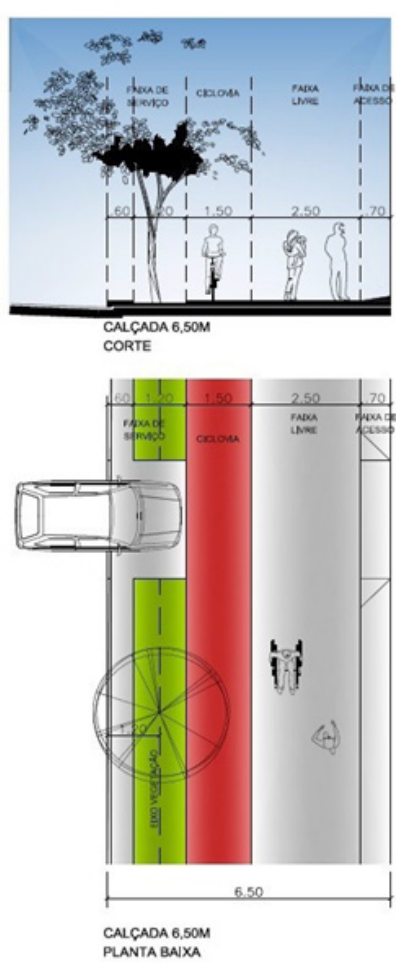

Fonte: Maringá, 2016. 
Para a análise da arborização nas praças foi elaborado um roteiro específico para cada árvore (Quadro 1), incluindo a marcação e situação das mesmas quanto aos principais aspectos exigidos pelas normas, como: presença e dimensão da área permeável $\left(\mathrm{m}^{2}\right)$, existência e distância de faixa pavimentada a partir do meio fio $(\mathrm{m})$, atendimento à localidade quanto à faixa de serviço, visualização se a área permeável está livre de obstáculos.

Quadro 1: Roteiro para análise das árvores.

\begin{tabular}{|l|l|l|l|}
\hline \multirow{4}{*}{ Árv Xossui área permeável de no mínimo 1,20x2,40m (2,88m²) } & Possui faixa pavimentada de 0,60m \\
\cline { 2 - 4 } & Sim: ( ) Na posição correta? S( )|N( ) & Não:( ) & Sim: ( ) Não: ( ) \\
\cline { 2 - 4 } & Esta dentro da área de serviço? & área permeavel livre de obstáculos (obs leve declive pra facilita) \\
\hline Sim: ( ) Não: ( ) & $\mathrm{S}(\mathrm{l}) \mathrm{N}($ ) & Rua: \\
\hline
\end{tabular}

Para análise das calçadas das praças elaborou-se um roteiro abordando os principais aspectos normativos para caracterização do rebaixamento das guias das calçadas, contendo os seguintes parâmetros: inclinação longitudinal, largura mínima, desnível entre o fim do rebaixamento e o leito carroçável, rebaixamento e largura da faixa de pedestres, presença ou ausência de sinalização tátil (Quadro 2).

Quadro 2: Roteiro para análise dos rebaixamentos de calçada.

\begin{tabular}{|c|c|c|c|c|c|}
\hline \multirow{2}{*}{ Rebaixamento $X$} & \multicolumn{2}{|l|}{$\mathrm{iL}$} & \multicolumn{2}{|c|}{ LM } & \multirow{2}{*}{$\begin{array}{c}\text { Praça } \\
\text { ( )PNM ( )PRT }\end{array}$} \\
\hline & $S() N():$ & $\%$ & $S($ ) $N():$ & $\mathrm{m}$ & \\
\hline$D$ & $\mathrm{FP}$ & & $\mathrm{PT}$ & & Rua: \\
\hline$\% \mathrm{~N}($ ) & $\mathrm{S}(\mathrm{)}) \mathrm{N}$ & & $S() N$ & & \\
\hline
\end{tabular}

\section{Onde:}

- iL: Inclinação Longitudinal máxima de 8,33\%;

- LM: Largura mínima de 1,50m;

- Praça: (Informa em qual praça se encontra esse rebaixamento);

- D: Se há desnível entre o fim do rebaixamento e o leito carroçável;

- FP: Se o rebaixamento possuía a mesma largura da faixa de pedestres;

- PT: Se o rebaixamento possuía alguma sinalização tátil;

- Rua: Informa para o lado de qual rua o mesmo se encontrava;

Ao final foram elaboradas sugestões de melhorias e readequações para as não conformidades verificadas nas calçadas analisadas.

Para este estudo, considerou-se as seguintes definições:

- Faixa de serviço se destina a acomodar mobiliários, árvores, arbustos e sinalizações. A NRM U-20001 determina uma largura fixa de 1,80m composta por $0,60 \mathrm{~m}$ de faixa pavimentada junto ao meio fio e 1,20m de faixa de permeabilidade, como exceção de calçadas de lotes pertencentes a Zona de Comércio Central ou Comércio e Serviços, onde nesses casos não haverá faixa de permeabilidade, e sim uma área não pavimentada de no mínimo 1,20m x 2,40m entorno de cada árvore (MARINGÁ, 2016); 
- Faixa livre se destina ao uso exclusivo e livre dos pedestres, livre de quaisquer obstáculos. A definição da sua largura será variável baseando-se na largura total a qual a calçada possui: largura mínima de 1,20m para calçadas com largura até 3,00m; 1,50m para calçadas com 4,00m; 2,50m para calçadas com 5,00m (MARINGÁ, 2016);

- Faixa de acesso, quando possível sua instalação, se destina a criar a concordância da calçada com a edificação, com largura fixa de $0,70 \mathrm{~m}$, podendo haver rampas para ajustar os níveis da calçada e o terreno, desde que não interfira na faixa livre (MARINGÁ, 2016).

\section{RESULTADOS E DISCUSSÕES}

Desde 1959 existe uma legislação voltada ao planejamento e gestão da cidade de Maringá, muito embora generalista em alguns aspectos. A lei municipal no 34/1959, designada com Código de Postura e Obras, determinava padrões e dimensões sobre as calçadas, o que mostra que desde o início havia uma preocupação do legislador sobre a temática. Segundo Albertin (2016), para calçadas maiores que 5,00 m de largura exigia-se a implementação do que hoje conhecemos de calçada ecológica, com área permeável de vegetação rasteira. Para calçadas de até 3,50 m de largura, exigia-se a presença de 1,00 metro de diâmetro de área permeável no entorno dos exemplares arbóreos (Fig. 6).

Figura 6: Padrão de passeio de Maringá no ano de 1959.

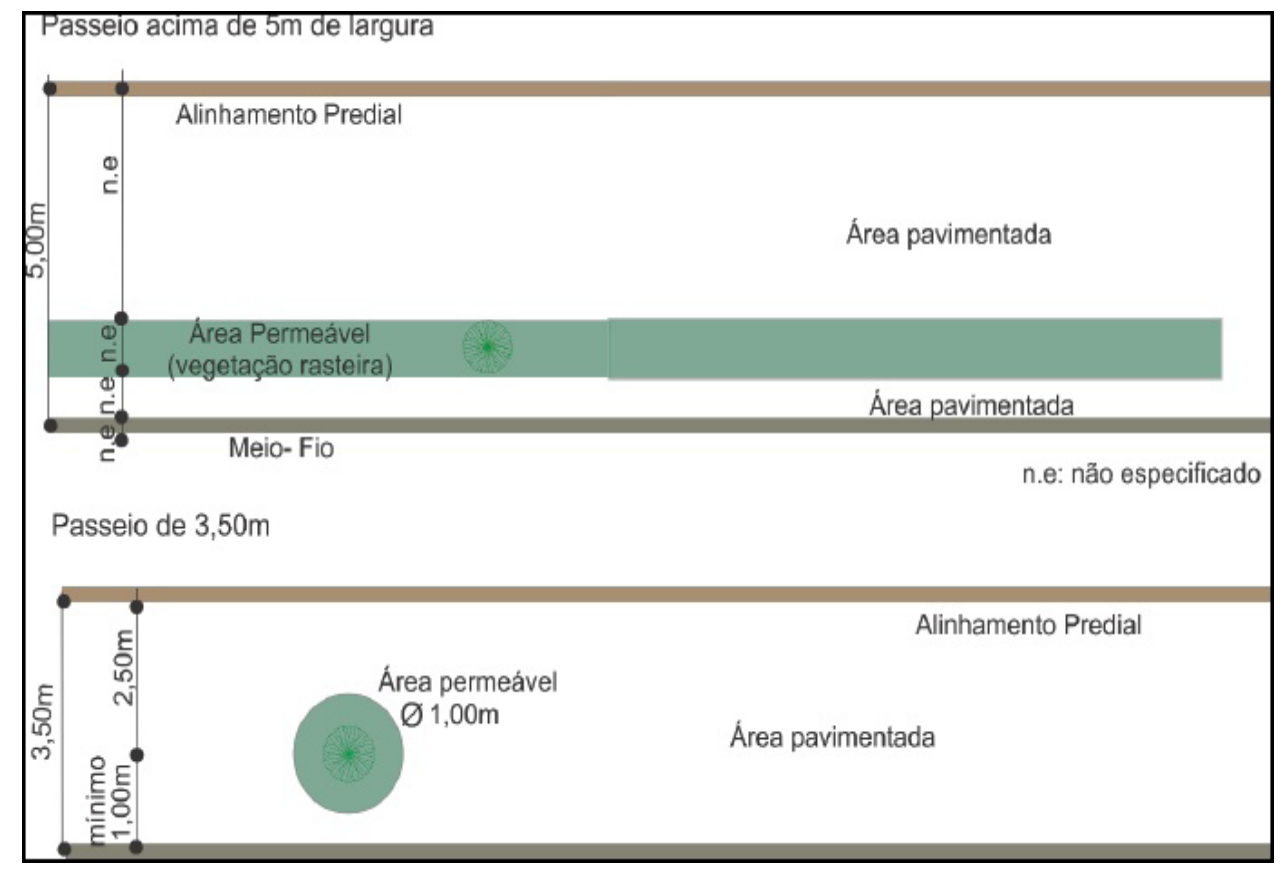

Fonte: Albertin, 2016.

O planejamento urbano no que tange a padronização de calçadas, deu-se nos primórdios do desenvolvimento da cidade. Atualmente a normatização vigente é a NRM U-20001, cujos parâmetros serão apresentados ao abordar os resultados. 
Considera-se que as calçadas devem ser desenhadas aos usuários, ou seja, aos pedestres. Deve ser dimensionado em função do uso e ocupação do solo. Em zonas multifamiliares ou zonas comerciais fatalmente ocorrerá uma intensa circulação de pedestres, daí a importância de dimensionar adequadamente e definir o tipo e mobiliária urbano apropriado (CASTELLO, 2008).

\section{Praça Raposo Tavares}

Ao avaliar os pisos da praça Raposo Tavares, observou-se se encontravam em péssimo estado (Fig. 7), com trincas, fissuras, buracos, ondulações e desplacamento do revestimento por toda sua extensão. Apesar do alto fluxo de pessoas que transitam diariamente pela Praça Raposo Tavares, o que se observa é que o poder público municipal falha ao não realizar manutenção adequada dos pisos desta praça. Neste aspecto, vem contra as afirmações de Castello (2008), onde o passeio em núcleos centrais deve ser elemento ativo, deve atuar como agente estimulador das possibilidades de encontro e de interação, sem atrapalhar na livre circulação dos transeuntes.

Registrou-se a ausência de sinalização tátil direcional, exigida pela NRM U-20001 para calçadas da ZCC. Também foi adotada uma largura de 4,00m para as calçadas que, segundo a NRM U-20001, deve possuir no mínimo 1,50m de largura de faixa livre, contínua e livre obstáculos, destinada ao uso dos pedestres.

Figura 7: Situação das calçadas na praça Raposo Tavares pela Tv. Guilherme de Almeida

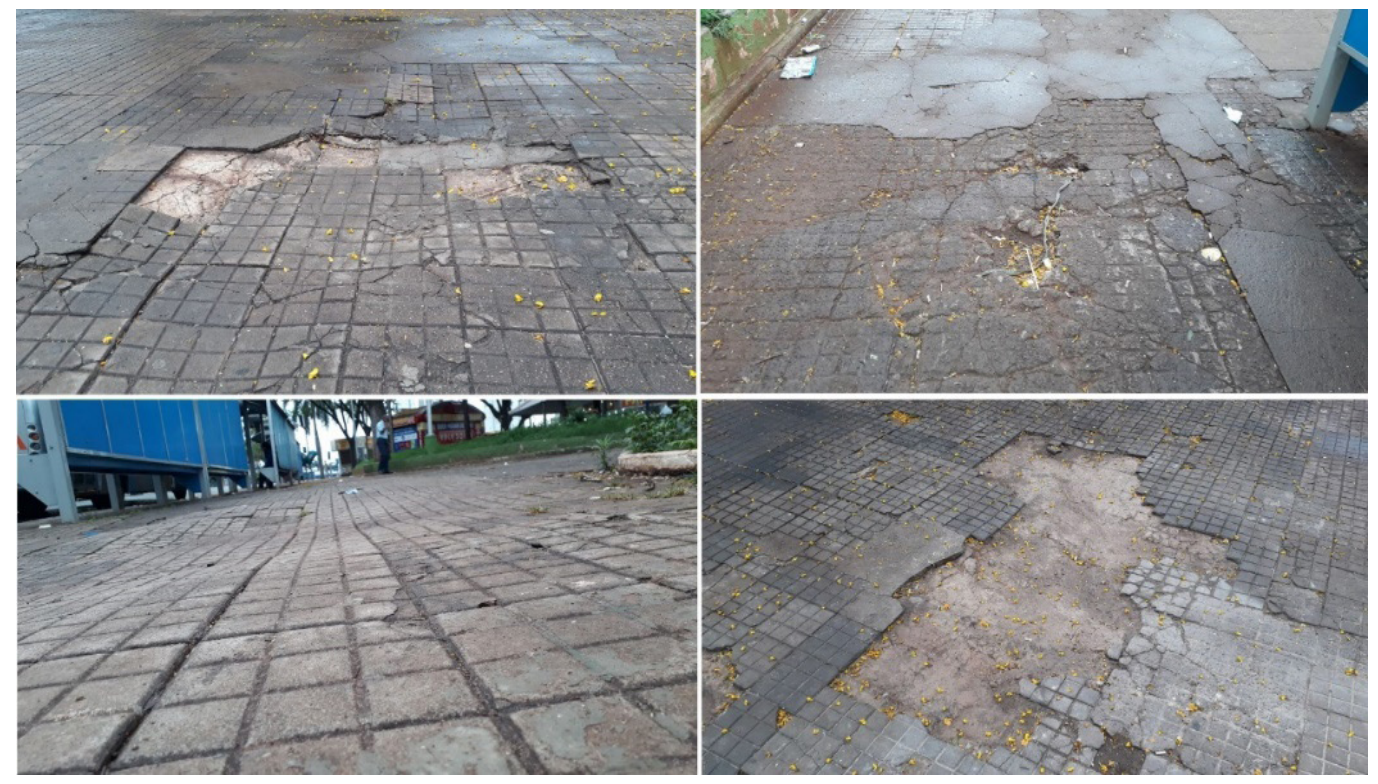

Fonte: os autores

Verificou-se nesta praça a presença de 14 abrigos de ônibus, possuindo dimensões individuais de aproximadamente 1,26 $\mathrm{m} \times 4,00 \mathrm{~m}$, no qual todos se localizavam fora da faixa de serviço. Mas mesmo ocupando uma média de 2,50 $\mathrm{m}$ junto a guia, em nenhum momento os abrigos de ônibus interferiram na largura mínima de faixa livre, e ainda, se os 
mesmos estivessem dentro dos limites da faixa de serviço de 1,80 $\mathrm{m}$, restaria espaço livre entre o abrigo e o leito carroçável de apenas $0,54 \mathrm{~m}$, o que impossibilitaria a passagem e uso de uma pessoa que estivesse contando com o auxílio de bengala, andador, muletas, cão-guia, dentre outros, como pode-se observar na Figura 8.

Figura 8: Largura resultante com a implantação do abrigo de ônibus, na praça Raposo Tavares.

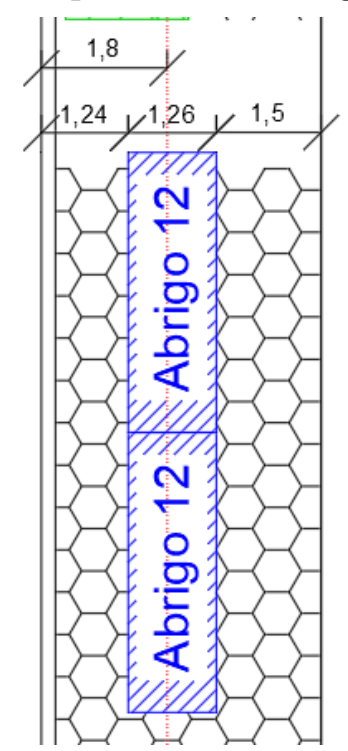

Fonte: os autores.

De acordo com Castello (2008) considera-se que passeios, apesar de ser um canal de circulação de pessoas, formam o espaço da cidade, onde estão agregados artefatos e equipamentos, que fazem parte da infraestrutura urbana das cidades, dentre eles a presença da arborização de acompanhamento viário. No total foram verificadas 16 árvores nas calçadas dessa praça, principalmente das espécies Tipuana tipu (Benth.) Kuntze (tipuana) e Caesalpinia pluviosa var. peltophoroides (Benth) G.P. Lewis (sibipiruna). A área média permeável no entorno das árvores é de $3,51 \mathrm{~m}^{2}$, valor este acima do mínimo exigido pela legislação municipal, que é de $2,88 \mathrm{~m}^{2}$ (Tab. 1).

Tabela 1: Situação dos parâmetros analisados na praça Raposo Tavares.

\begin{tabular}{|c|c|c|}
\hline Parâmetros analisados & Situação na praça Raposo Tavares & Legislação vigente* \\
\hline Área permeável & $3,51 \mathrm{~m}^{2}$ & Mín. 2,88 m² \\
\hline Largura total ocupada junto ao meio fio & $2,06 \mathrm{~m}$ & $1,80 \mathrm{~m}$ \\
\hline $\begin{array}{l}\text { Faixa livre (largura livre disponível da } \\
\text { calçada onde havia a existência das árvores } \\
\text { considerando as calçadas com largura de } \\
4,00 \mathrm{~m}) ;\end{array}$ & $1,94 \mathrm{~m}$ & Mín. 1,50 m \\
\hline Faixa pavimentada junto ao meio fio & $0,35 \mathrm{~m}$ & $0,60 \mathrm{~m}$ \\
\hline
\end{tabular}

*De acordo com a Norma Regulamentadora Municipal de Maringá U-20001, 2016.

Também 37,5\% das árvores estão localizadas de forma adequada, ou seja, situam-se dentro da faixa de serviço; apenas $6,25 \%$ das árvores se apresentam na faixa pavimentada 
de 0,60 m junto ao meio fio. 50,0\% apresentam área permeável maior ou igual a $2.88 \mathrm{~m}^{2}$, ou seja, de acordo com o que é estabelecido por lei (Tab. 2).

Tabela 2: Situação das árvores das calçadas da praça Raposo Tavares

\begin{tabular}{|c|c|c|}
\hline Quesito & Quantidade & Ocorrência (\%) \\
\hline Situa-se dentro da faixa de serviço & $6 / 16$ & 37,5 \\
\hline Possui faixa pavimentada de $0,60 \mathrm{~m}$ junto ao meio fio & $1 / 16$ & 6,25 \\
\hline Possui área permeável $\geq 2,88 \mathrm{~m}^{2}$ & $8 / 16$ & 50 \\
\hline $\begin{array}{l}\text { Possui área permeável sem obstrução com caminho livre para escoamento das } \\
\text { águas pluviais }\end{array}$ & $16 / 16$ & 100 \\
\hline
\end{tabular}

Fonte: os autores

Em alguns casos observou-se que a árvore se encontrava dentro do limite da faixa de serviço de 1,80 m, porém com uma área permeável de apenas 1,22 m², que poderá trazer danos ao sistema radicular na reposição de água e os nutrientes à árvore (Fig. 9). Tal fato, poderá também desencadear a danificação do piso das calçadas pelo afloramento do sistema radicular (ALBERTIN, 2016).

Figura 9: Vista do tronco de árvore e área permeável em desacordo com a norma técnica vigente, na Praça Raposo Tavares, próximo a Tv. Júlio de M. Filho

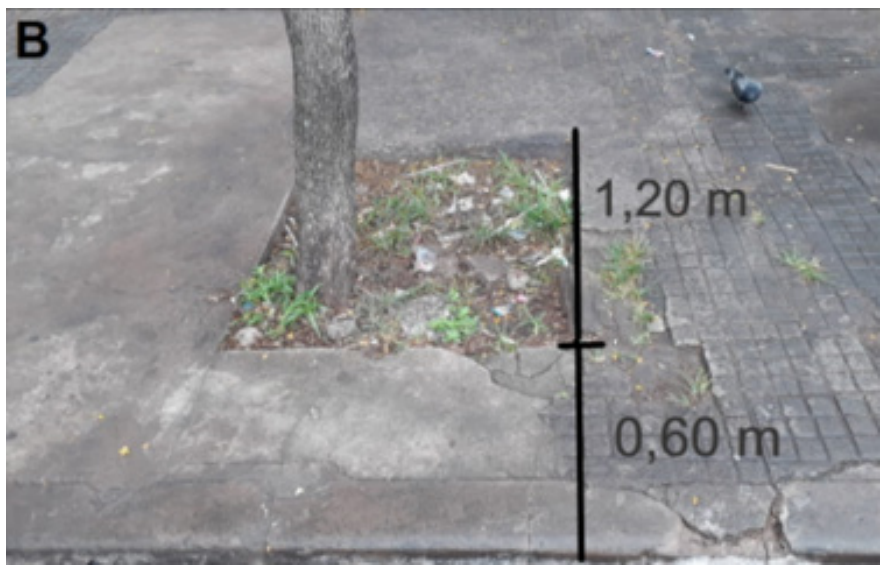

Fonte: foto dos autores.

Na figura 10 (A e B) observa-se dois exemplos distintos: em 10A a área permeável da árvore não possui as dimensões recomendadas de 1,20m x 2,40m, dimensão adequada para um caso hipotético onde, somando o lado da largura da árvore de 1,20m com os 0,60m de faixa pavimentada junto ao meio fio exigidos por norma, resultaria em 1,80m de largura, a largura da faixa de serviço estipulada pela norma. Contudo, como nesse caso não possuía os $0,60 \mathrm{~m}$ de faixa pavimentada junto ao meio fio, e sim apenas $0,20 \mathrm{~m}$ do próprio meio fio, acabou ocupando 1,75m da faixa de serviço estando assim dentro do limite de 1,80m, e possuindo $2,88 \mathrm{~m}^{2}$ de área permeável, o mínimo exigido por norma. Neste caso a única não conformidade foi a falta de faixa pavimentada de $0,60 \mathrm{~m}$ meio ao meio fio. 
Em 10B, havia até mais do que o exigido de faixa pavimentada junto ao meio fio, com $0,70 \mathrm{~m}$. No entanto as dimensões da árvore não foram o suficiente para atingir os 2,88 $\mathrm{m}^{2}$ de área permeável exigido, e embora sua posição se encontrasse dentro da faixa de serviço, havia apenas $1,60 \mathrm{~m}^{2}$ de área permeável.

Figura 10. Comparativo da situação de duas árvores situadas na calçada da R. Joubert de Carvalho, na praça Raposo Tavares.

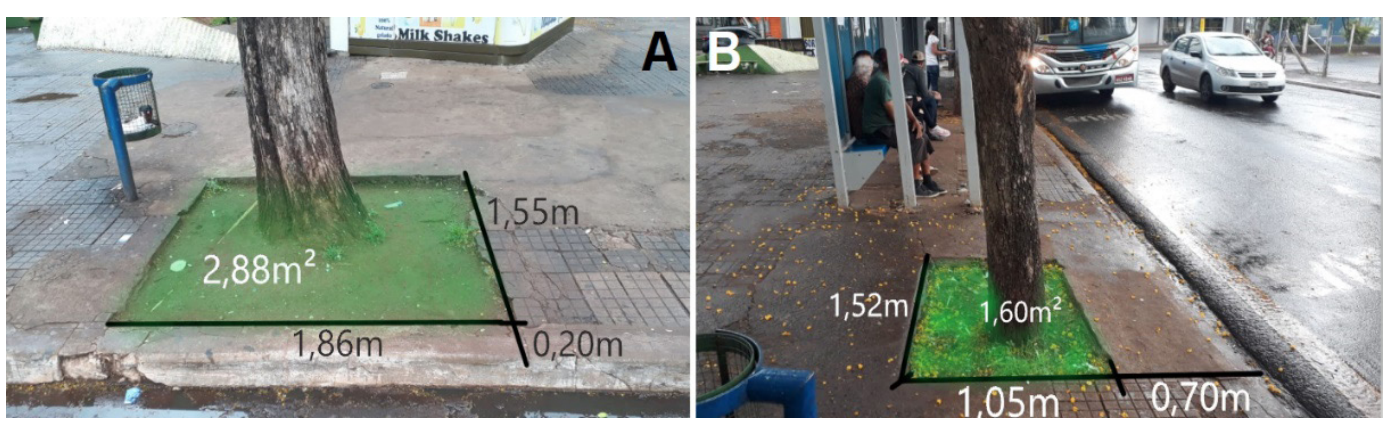

Fonte: fotos dos autores.

Quanto aos rebaixamentos de calçadas, foram encontradas seis guias rebaixadas, e a disposição das mesmas quanto aos principais critérios normativos estabelecidos por norma (Tab. 3).

Tabela 3: Situação dos rebaixamentos de calçada da praça Raposo Tavares

\begin{tabular}{c|c|c}
\hline Quesito & Quantidade & Ocorrência (\%) \\
\hline Inclinação longitudinal máxima de 8,33\% & $4 / 6$ & 66,66 \\
\hline Largura mínima de 1,50 m & $2 / 6$ & 33,33 \\
\hline $\begin{array}{c}\text { Não havia desnível entre o término e o leito carroçável (desconsiderados os } \\
\text { desníveis dados como desprezíveis) }\end{array}$ & $4 / 6$ & 66,66 \\
\hline Possui algum tipo de sinalização tátil & $2 / 6$ & 33,33 \\
\hline Alinhado a faixa de pedestres & $4 / 6$ & 66,66 \\
\hline
\end{tabular}

Fonte: os autores.

A figura 11 apresenta registro fotográfico da guia rebaixada com inclinação longitudinal de $7,69 \%$, alinhada com a faixa de pedestres e sem desnível em seu término com o leito carroçável. Possui a largura mínima exigida por norma de 1,50 m, contudo não havia nenhum tipo de sinalização tátil e inclinação transversal ainda que apresentando um degrau de mais de 3,0 centímetros, em desacordo com a normatização vigente. 
Figura 11: Rebaixamento de calçada praça Raposo Tavares pela R. Joubert de Carvalho
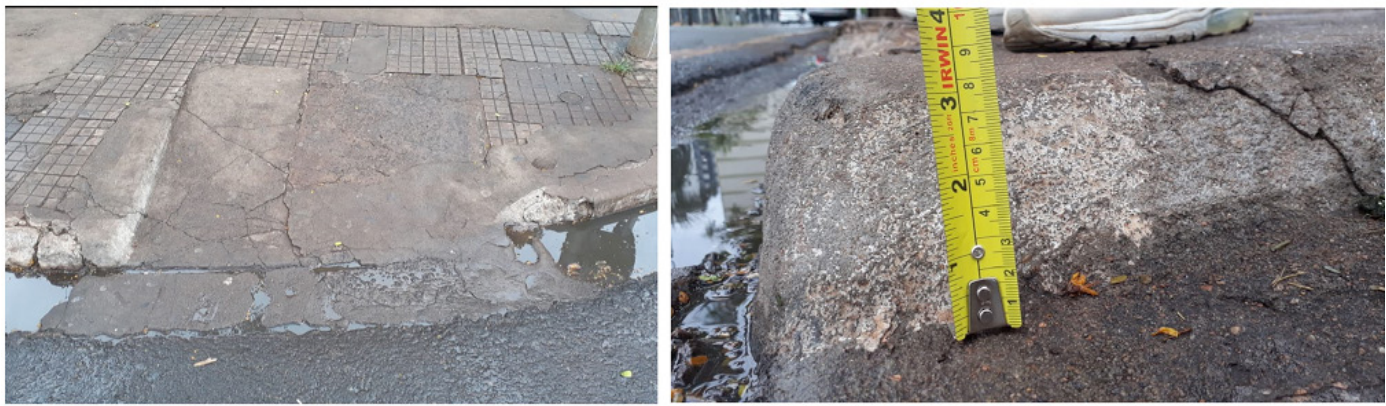

Fonte: fotos dos autores.

Houve também um caso onde havia um recuo de $1,80 \mathrm{~m}$ da calçada e ao lado a presença de uma construção de aproximadamente 4,38 m x 4,02 m, assim ocupando o espaço de toda a largura da calçada (Fig. 12A). Após essa construção havia um comércio provisório com aproximadamente as mesmas dimensões, também ocupando toda a largura da calçada pelo lado da Tv. Guilherme de Almeida, impossibilitando o trânsito de pedestres nesse ponto. A mesma situação da Figura 12B, entre a barraca de cocada e o suporte que a sustenta, tendo apenas $0,85 \mathrm{~m}$ de passagem e não sendo possível a locomoção de pessoas portadoras de deficiência (PcD), para as quaisl se destina no mínimo $0,90 \mathrm{~m}$.

Figura 12: Obstáculos construtivos na calçada da praça Raposo Tavares

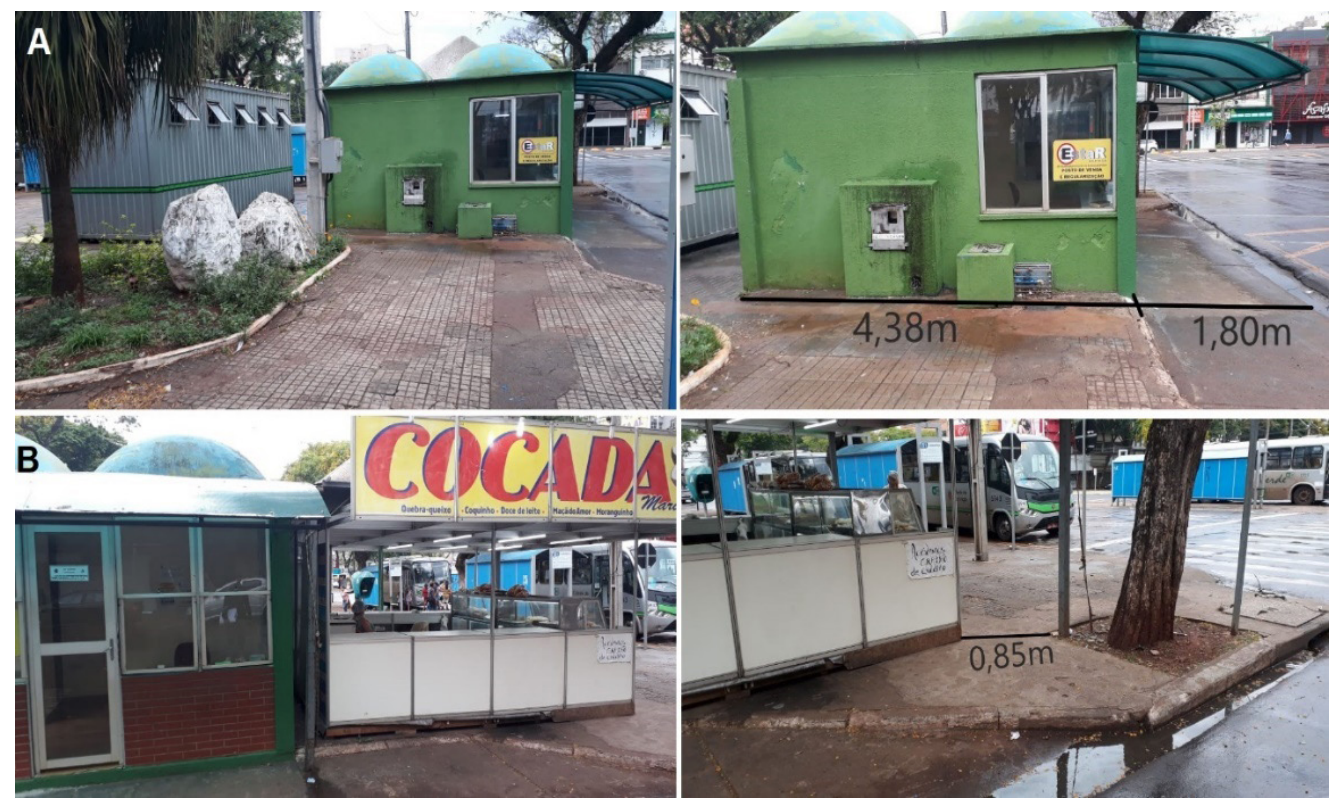

Fonte: fotos dos autores.

\section{Praça Napoleão Moreira Da Silva}

Foi observada na praça Napoleão Moreira da Silva uma largura média de 5,00 m, ainda que em alguns pontos tenha havido um pouco de variação na largura da calçada. 
Nesse caso, devendo possuir no mínimo 2,50m de faixa livre, atende a NRM U-20001. A calçada não possuí faixas de acesso por não haver edificação na praça.

Quanto ao piso, não havia sinalização tátil em nenhuma parte de toda a extensão da calçada. Verificou-se uma situação precária do piso (Fig. 13), com ocorrência de buracos, desplacamento do revestimento, desnivelamentos e trincas, e em certo ponto a existência de um recapeamento feito por cima do revestimento, gerando degraus de até 2 centímetros de desnivelamento, o que pode se caracterizar obstáculos. Também se observou a presença de obstáculos como um buraco e um desnível formado por uma caixa da Companhia de Abastecimento de Água, ao passo que a norma exige que tampas de caixa de inspeção ou visita devem ser totalmente niveladas com o piso onde se encontram.

Figura 13: Situação do piso da calçada da praça Napoleão Moreira da Silva

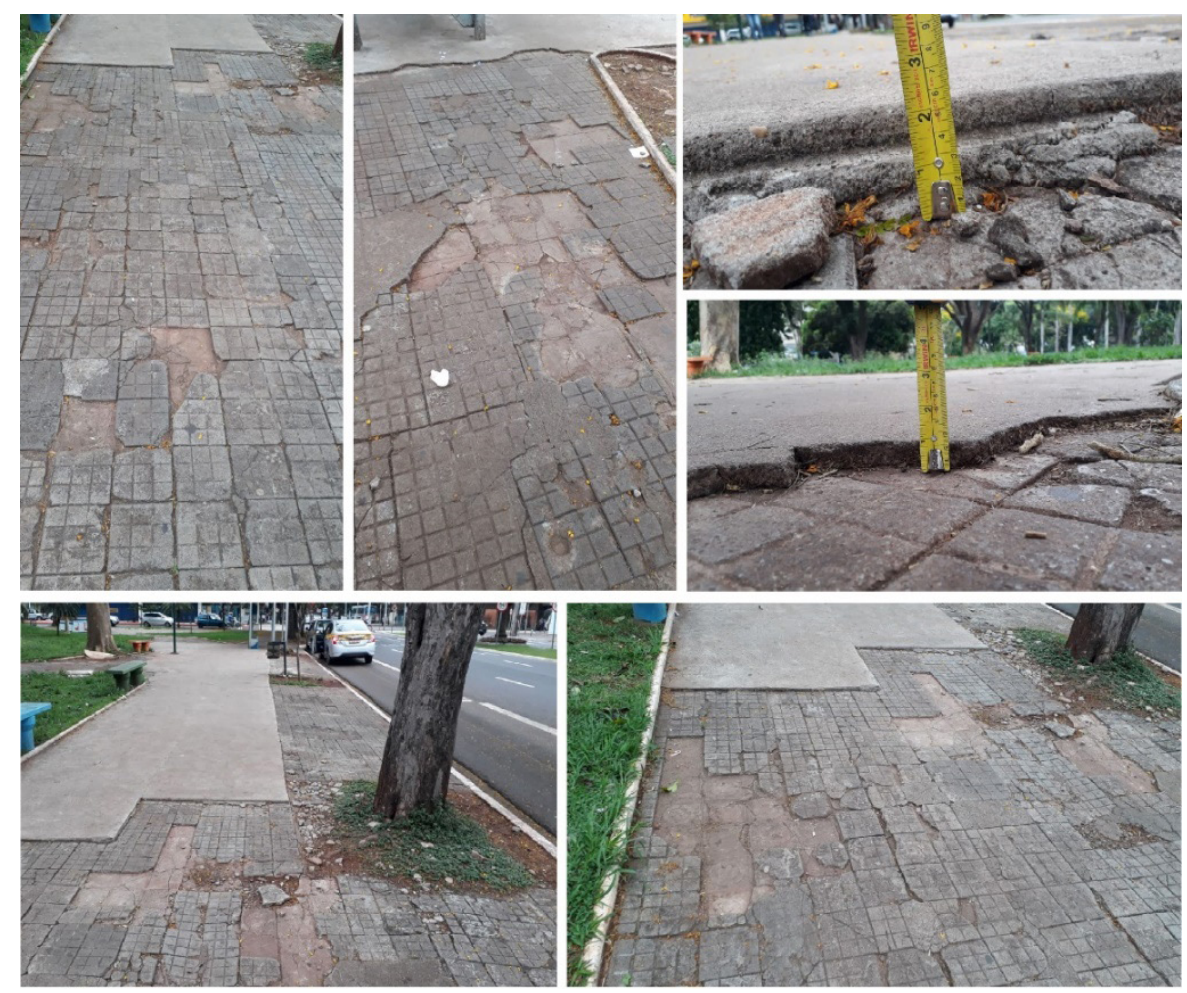

Fonte: fotos dos autores.

Há dois abrigos de táxi na praça, um deles ocupando 2,86 $\mathrm{m}$ junto ao meio fio, extrapolando desta forma o limite da faixa de serviço de 1,80 m. A Figura 14 mostra que o abrigo de táxi localiza-se em um local em que há redução drástica da faixa livre, onde transversalmente havia uma largura de apenas 1,02 m (deveria ter no mínimo 2,50 m para calçada com largura de 5,00m), o que caracteriza como obstáculo tanto para PcD e/ou mobilidade reduzida quanto para quem não possua nenhuma dessas necessidades especiais. 
Figura14: Não conformidade quanto a faixa livre por conta de um obstáculo fixo (abrigo de taxi), na praça Napoleão Moreira da Silva.
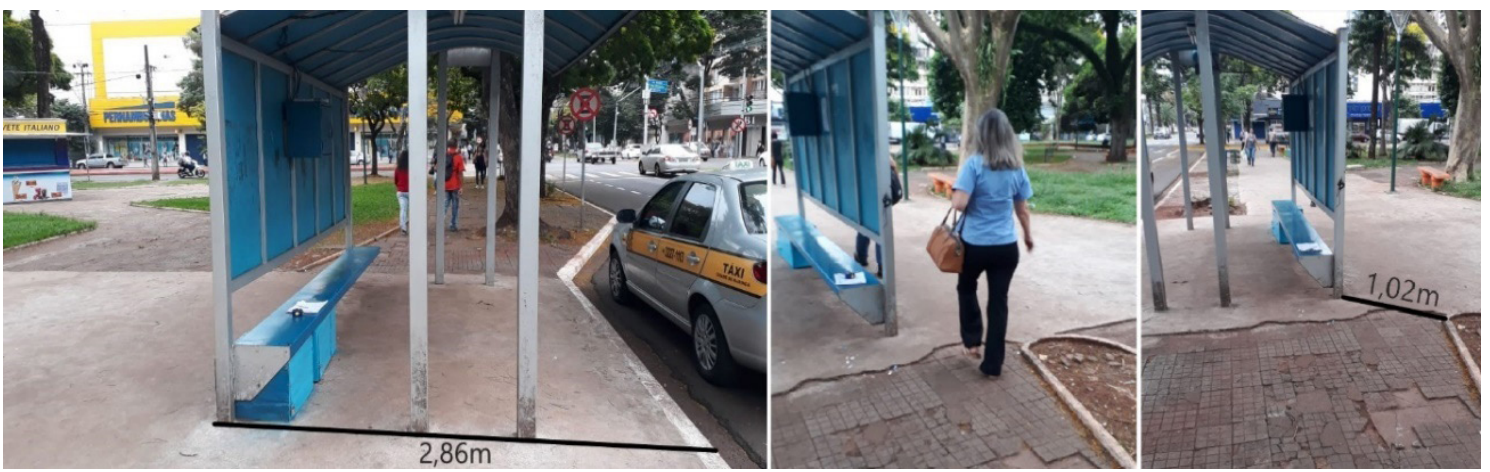

Fonte: fotos dos autores.

Foram verificadas 46 árvores nas calçadas da praça Napoleão Moreira da Silva, sendo representadas principalmente pelas espécies Tipuana tipu (Benth.) Kuntze (tipuana) e Caesalpinia pluviosa var. peltophoroides (Benth) G.P. Lewis (sibipiruna).

Tabela 4: Situação dos parâmetros analisados na praça Napoleão Moreira da Silva.

\begin{tabular}{c|c|c}
\hline Parâmetros analisados & $\begin{array}{c}\text { Situação na praça Napoleão } \\
\text { Moreira da Silva }\end{array}$ & Legislação vigente* \\
\hline Área permeável & $4,43 \mathrm{~m}^{2}$ & Mín. 2,88 $\mathrm{m}^{2}$ \\
\hline Largura total ocupada junto ao meio fio & $2,43 \mathrm{~m}$ & $1,80 \mathrm{~m}$ \\
\hline $\begin{array}{c}\text { Faixa livre (largura livre disponível da calçada onde havia } \\
\text { a existência das árvores considerando as calçadas com } \\
\text { largura de 5,00m); }\end{array}$ & $2,57 \mathrm{~m}$ & Mín. 2,50 m \\
\hline Faixa pavimentada junto ao meio fio & $0,34 \mathrm{~m}$ & $0,60 \mathrm{~m}$ \\
\hline
\end{tabular}

*De acordo com a Norma Regulamentadora Municipal de Maringá U-20001, 2016.

Todas as árvores estão localizadas de forma inadequada, fora da faixa de serviço - 10,87\% das árvores se apresentam na faixa pavimentada de 0,60 m junto ao meio fio; $97,83 \%$ se apresentam na área permeável, maior ou igual a $2.88 \mathrm{~m}^{2}$ (Tab. 5).

Tabela 5. Situação das árvores da praça Napoleão Moreira da Silva.

\begin{tabular}{|c|c|c|}
\hline Quesito & Quantidade & Ocorrência (\%) \\
\hline Situa-se dentro da faixa de serviço & $0 / 46$ & 0 \\
\hline Possui faixa pavimentada de $0,60 \mathrm{~m}$ junto ao meio fio & $5 / 46$ & 10,87 \\
\hline Possui área permeável $\geq 2,88 \mathrm{~m}^{2}$ & $45 / 46$ & 97,83 \\
\hline $\begin{array}{c}\text { Possui área permeável sem obstrução com caminho livre para escoamento das } \\
\text { águas pluviais }\end{array}$ & $46 / 46$ & 100 \\
\hline
\end{tabular}

Fonte: os autores.

Na praça Napoleão Moreira da Silva, na esquina da R. Santos Dumont com a R. Ver. Basílio Sautchuk, a calçada apresentou uma variação em sua largura por uma extensão de 
aproximadamente 35,00 m, onde dentro desse espaço apresentou-se uma largura média de 4,41 m, pode ser observado essa variação na Figura 15 (A e B).

Por conta da variação na largura, acrescido da posição irregular das árvores, verificouse que não foi cumprida a largura mínima de faixa livre exigida pela legislação. Na figura 15A, observa-se que a calçada apresentou uma largura total de 4,32 m, restando como faixa livre apenas 1,83 m; na figura 15B, a calçada apresentou uma largura total 4,51 m, e por interferência da locação da árvore, uma disponibilidade de apenas 1,47 m de faixa livre. Relacionando-se essas duas situações com as normas vigentes, se percebe que se as árvores estivessem alocadas dentro da faixa de serviço de 1,80 m, mesmo com a variação da largura da calçada, teria sido atingido o limite mínimo de faixa livre.

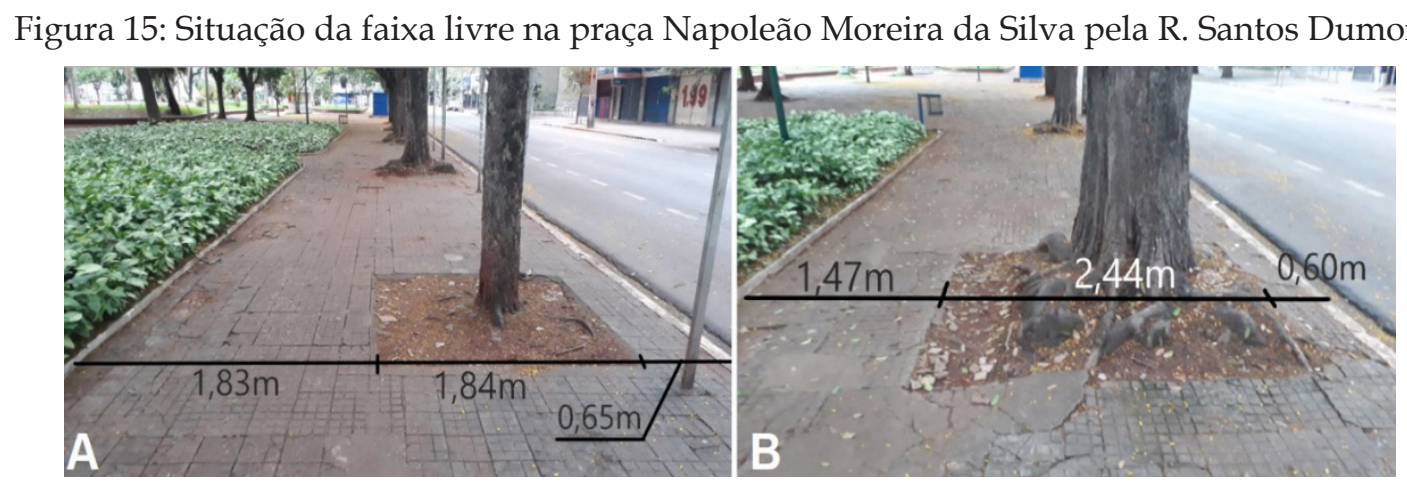

Fonte: fotos dos autores.

Foram identificados nove rebaixamentos de guia de calçadas, onde a maioria apresentou inclinação longitudinal máxima de 8,33\%; mais da metade possui algum tipo de sinalização tátil e a maioria está alinhada à faixa de pedestres. No entanto apenas 22,22 \% apresentaram-se com largura mínima de 1,50 m e em 33,33 \% das calçadas não havia desnível entre o término e o leito carroçável, o que é um agravante problema para pessoas com mobilidade reduzida (Tab. 6).

Tabela 6: Rebaixamentos de calçada da praça Napoleão Moreira da Silva

\begin{tabular}{|c|c|c|}
\hline Quesito & Quantidade & Ocorrência (\%) \\
\hline Inclinação longitudinal máxima de 8,33\% & $7 / 9$ & 77,78 \\
\hline Largura mínima de $1,50 \mathrm{~m}$ & $2 / 9$ & 22,22 \\
\hline $\begin{array}{c}\text { Não havia desnível entre o término e o leito carroçável (desconsiderados os } \\
\text { desníveis dados como desprezíveis) }\end{array}$ & $3 / 9$ & 33,33 \\
\hline Possui algum tipo de sinalização tátil & $6 / 9$ & 66,66 \\
\hline Alinhado a faixa de pedestres & $7 / 9$ & 77,78 \\
\hline
\end{tabular}

Fonte: os autores.

Ao levantar os principais problemas das guias rebaixadas, observou-se que uma das guias estava em total desacordo com as normas (Fig. 16). Neste caso a guia possuía uma inclinação longitudinal de aproximadamente 12,76\%, presença de degraus, largura 
média de apenas 1,05 m, ausência de sinalização tátil e desnível entre o término e o leito carroçável. O único aspecto considerado em conformidade era o fato de seguir a direção da faixa de pedestres.

Figura 16: Rebaixamento de calçada não conforme na praça Napoleão Moreira da Silva.

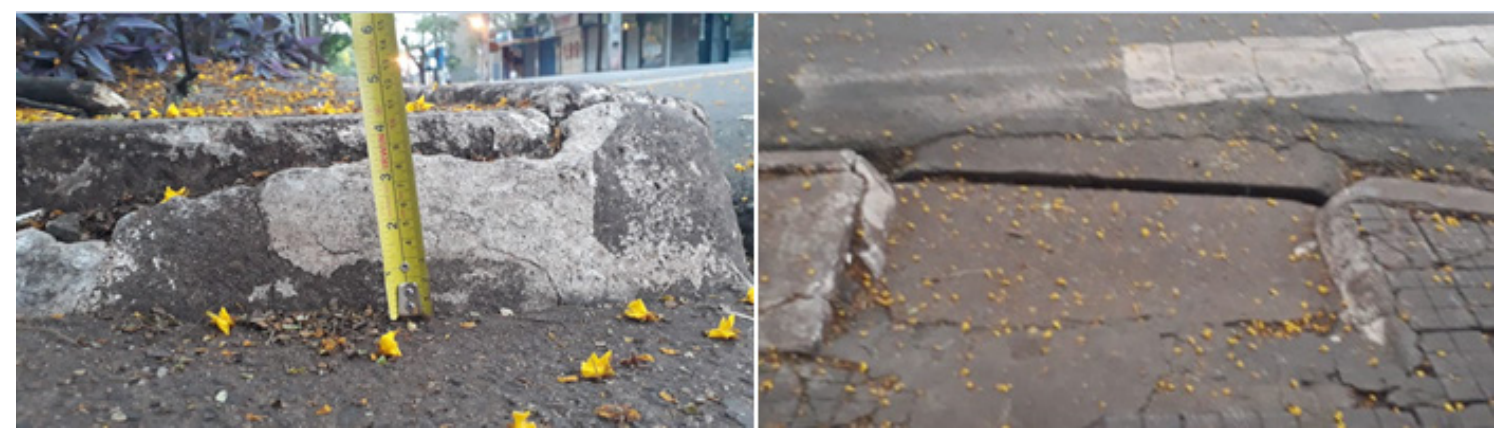

Fonte: fotos dos autores.

De todos os rebaixamentos de calçada analisados, nenhum deles se encontravam de acordo com os critérios analisados. Na figura 17 pode-se observar como deveriam ser esses rebaixamentos em conformidade com as exigências normativas.

Figura 17: Rebaixamento de calçada em conformidade com as normas.

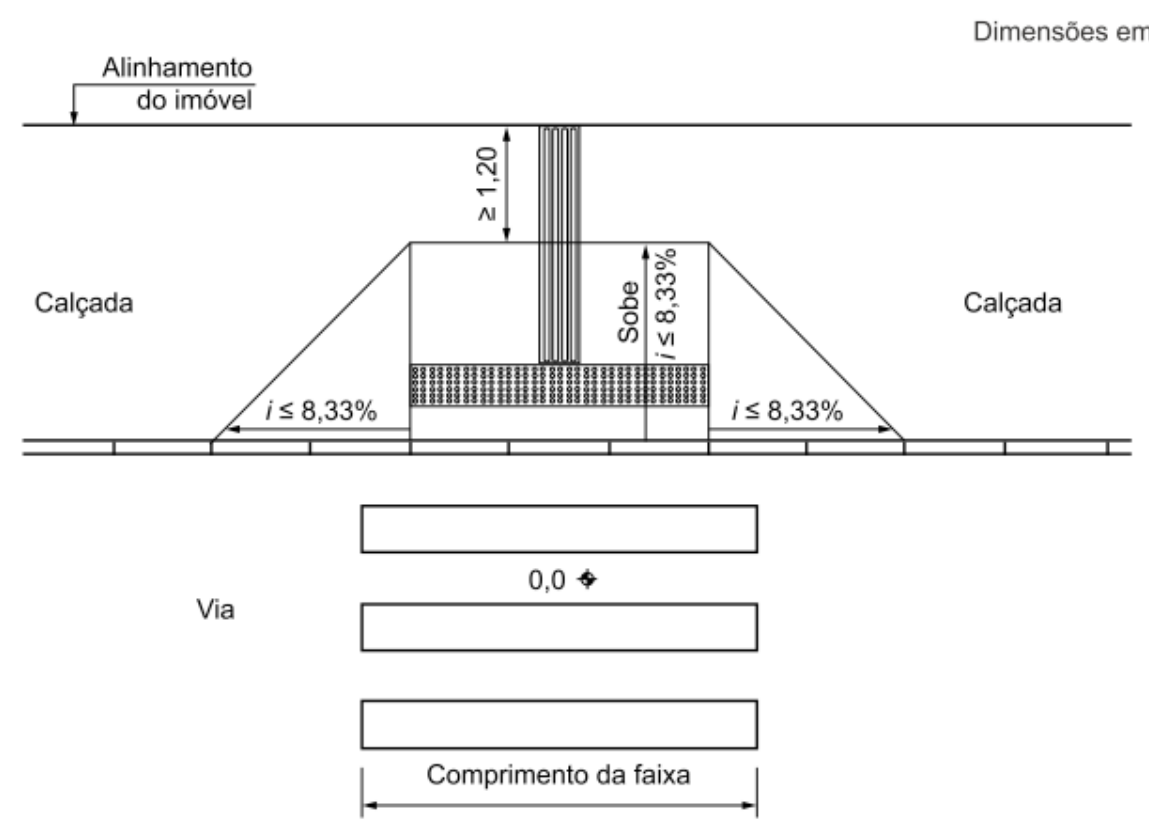

Fonte: ABNT NBR 9050 (2015, p. 80) 


\section{CONSIDERAÇÕES FINAIS}

Ao analisar a situação das calçadas das praças Raposo Tavares e Napoleão Moreira da Silva, foi percebido que mesmo havendo normatização nacional e municipal que estabelece critérios a serem cumpridos, não somente quanto as dimensões como também em casos específicos de acessibilidade, muitas vezes estas não foram cumpridas. Identificou-se não conformidades nas guias rebaixadas das calçadas de ambas as praças, aparentando em alguns casos, a intenção única de implantar o rebaixamento independente se ali isto seria permitido ou não.

Árvores irregulares, em situações de localização fora da faixa de serviço, ausência da faixa pavimentada junto a guia de $0,60 \mathrm{~cm}$, indisponibilidade da área permeável exigida e deterioração do piso por conta das raízes foram outros casos de não conformidade verificados nas calçadas das praças. Além do péssimo estado do piso dessas calçadas verificou-se também, em alguns casos, ausência de sinalização tátil direcional, o que impossibilita a utilização de um deficiente visual de forma autônoma.

A presença de obstáculos construtivos tomando toda a calçada e trechos onde a largura da faixa livre possuí dimensão abaixo do estabelecido por norma apresentam dificuldades para travessia até para pessoas que não apresentam nenhum tipo de deficiência.

Tendo em vista que as análises feitas foram nas calçadas no entorno de duas praças muito movimentadas, localizadas na área central da cidade, cujo responsável é o poder púbico municipal, nos leva a pensar e refletir como estarão as calçadas localizadas em zonas e bairros mais afastados do centro, residenciais, onde o responsável pelo estado da calçada é o proprietário do imóvel. Isso é temática para futuros trabalhos.

\section{REFERÊNCIAS}

ALBERTIN, R.M. Pelas Ruas de Maringá: arborização de acompanhamento viário e os parâmetros de uso e ocupação do solo. Maringá, 2016. Tese (Doutorado em Geografia) - Universidade Estadual de Maringá, UEM. Disponível em: https://pt.scribd.com/document/350167014/ALBERTIN-Pelas-Ruasde-Maringa-Arborizacao-de-Acompanhamento-Viario-e-Os-Parametros-de-Uso-e-Ocupacao-Do-Solo Acesso em: 06 ago. 2018.

ALMEIDA, E.P.; BORTOLUZZI, M.G.; GIACOMINI, L.B. Mobilidade e Acessibilidade Urbana. In: SEMINARIO NACIONAL DE CONSTRUÇÕES SUSTENTÁVEIS, 2, 2013, Passo Fundo. Anais... p. 1-7. Disponível em: https://www.imed.edu.br/Uploads/Mobilidade\%20e\%20Acessibilidade\%20Urbana. pdf Acesso em: 21 mar. 2018.

ANGEOLETTO, F.; SANTOS, J.W.M.C.; SANZ, J.P.R. et al. Tipología socio-ambiental de las ciudades medias de Brasil: aportes para un desarrollo urbano sostenible. Urbe - Revista Brasileira de Gestão Urbana, v. 8, n. 2, p. 272-287, 2016.

ABNT - Associação Brasileira de Normas Técnicas. NBR 9050: Acessibilidade a edificações, mobiliário, espaços e equipamentos urbanos. 3 ed. Rio de Janeiro, 2015. p. 148, Disponível em: http://www.ufpb. br/cia/contents/manuais/abnt-nbr9050-edicao-2015.pdf Acesso em: 28 fev. 2018.

BOVO, Marcos Clair. Áreas verdes urbanas, imagem e uso: um estudo geográfico sobre a cidade de Maringá - PR. Presidente Prudente, 2009. Tese (Doutorado em Geografia) - Universidade Estadual Paulista Júlio de Mesquita Filho, UNESP. 
BRASIL. Constituição da República Federativa do Brasil. Brasília: Senado Federal, 1988. Disponível em: http://www.planalto.gov.br/ccivil_03/constituicao/constituicaocompilado.htm Acesso em: 28 dez. 2018.

BRASIL. Lei $\mathbf{n}^{\mathbf{0}} \mathbf{1 2 . 5 8 7}$ de 03/jan./2012. Institui as diretrizes da Política Nacional de Mobilidade Urbana; revoga dispositivos dos Decretos-Leis $n^{\text {os }}$ 3.326, de 3 de junho de 1941, e 5.405, de 13 de abril de 1943, da Consolidação das Leis do Trabalho (CLT), aprovada pelo Decreto-Lei no 5.452, de $1^{\circ}$ de maio de 1943, e das Leis nos5.917, de 10 de setembro de 1973, e 6.261, de 14 de novembro de 1975; e dá outras providências. Brasília, 2012. Disponível em: http://www.planalto.gov.br/CCIVIL_03/_Ato2011-2014/2012/Lei/ L12587.htm Acesso em: 03 jan. 2019.

BRASIL. Condições de vida das pessoas com deficiência no Brasil: Pesquisa de opinião pública nacional. p.32, 2010. Disponível em: https://www.senado.gov.br/senado/datasenado/pdf/datasenado/ DataSenado-Pesquisa-Condicao_de_vida_das_pessoas_com_deficiencia_no_Brasil.pdf Acesso em: 22 mar. 2018.

CASTELLO, I.R. Bairros, loteamentos e condomínios: elementos para o projeto de novos territórios habitacionais. Porto Alegre: Ed. UFRGS, 2008.

DE ANGELIS, B.L.D.; DE ANGELIS NETO, G. A praça no contexto da engenharia urbana - metodologia de avaliação. Acta Scientarum, v. 21, n. 4, p. 941-948, 1999. Disponível em: http://periodicos.uem.br/ ojs/index.php/ActaSciTechnol/article/view/3167/2377 Acesso em: 28 dez. 2018.

GOMIDE, A.A.; GALINDO, E.P. A mobilidade urbana: uma agenda inconclusa ou o retorno daquilo que não foi. Estudos avançados, v. 27, n. 79, p. 27-39, 2013.

GOOGLE. Google Earth. Versão 7.3.2.5491. 2018. Disponível em <https://earth.google.com/web/> Acesso em 27 dez. 2018.

HOWARD, Ebenezer. Garden Cities of Tomorrow. 2.ed. London: Sonnenschein, 1902.

IBGE - Instituto Brasileiro de Geografia e Estatística. Censo demográfico 1960-2010. Rio de Janeiro, 2010. Disponível em: https://censo2010.ibge.gov.br/sinopse/index.php?dados=8 Acesso em: 21 mar. 2018.

IBGE - Instituto Brasileiro de Geografia e Estatística. Censo demográfico 2010: Características gerais da população, religião e pessoas com deficiência. Rio de Janeiro, 2010. Disponível em: https:// biblioteca. ibge.gov.br/visualizacao/periodicos/94/cd_2010_religiao_deficiencia.pdf Acesso em: 22 mar. 2018.

IBGE - Instituto Brasileiro de Geografia e Estatística. Censo amostra - Pessoas com deficiência: Maringá. 2010.Disponívelem:https://cidades.ibge.gov.br/brasil/pr/maringa/pesquisa/23/23612?detalhes=true Acesso em: 08 ago. 2018.

IBGE - Instituto Brasileiro de Geografia e Estatística. Projeção de população: revisão 2018. Rio de Janeiro, 2018. Disponível em: https://agenciadenoticias.ibge.gov.br/agencia-sala-de-imprensa/2013-agenciade-noticias/releases/21837-projecao-da-populacao-2018-numero-de-habitantes-do-pais-deve-parar-decrescer-em-2047 Acesso em: 01 maio 2019.

IBGE - Instituto Brasileiro de Geografia e Estatística. Panorama Cidades - Maringá. 2019. Disponível em: https://cidades.ibge.gov.br/brasil/pr/maringa/panorama Acesso em: 29 maio 2019.

MARK, R.M. The Urban Transformation of the Developing World. Science, n. 319, p. 761-764, 2008. DOI: 10.1126/science.1153012.

MARINGÁ. NRM U-20001: das calçadas - desenho, acessibilidade e mobilidade. Maringá, 2016. p. 18. Disponível em: http://sisweb.maringa.pr.gov.br:81/formularioProcesso/arquivos/pag_4_ legisla\%C3\%A7\%C3\%A3o/9_NRM_Normas_Regulamentares_Municipais/NRM\%20cal\%C3\%A7adas. pdf Acesso em: 14 ago. 2018.

MARINGÁ HISTÓRICA, 2018. Disponível em: http://www.maringahistorica.com.br Acesso em: 14 ago. 2018.

MENEGUETTI, K.S.; REGO, R.L. O território e a paisagem: a formação da rede de cidades no norte do Paraná e a construção da forma urbana. Paisagem Ambiente: Ensaios, São Paulo, n. 25, p.37-54, 2008. Disponível em: http://www.revistas.usp.br/paam/article/view/40258/43124 Acesso em: 20 ago. 2018 
PROGRAMA BRASILEIRO DE ACESSIBILIDADE URBANA. Brasil Acessível: construindo a cidade acessível. Brasília, 2006.

RUMBLE, H.; ANGEOLETTO, F.; CONNOP, S. et al. Understanding and applying ecological principles in cities. In: LEMES de LOLIVEIRA, F.; MELL, I. Planning Cities with Nature: : Theories, Strategies and Methods. Amsterdam: Springer Nature, 2019. p. 217-234.

Data de submissão: 03/ jan./ 2019

Data e aceite: 28 / jun./ 2019 